\title{
COMPARISON OF INFLUENCE OF PULSED EFFECTS OF MAGNETIC AND ELECTRIC FIELDS ON STRESSED STATE OF WELDED JOINTS OF ALUMINIUM ALLOY AMG6
}

\author{
L.M. LOBANOV ${ }^{1}$, I.P. KONDRATENKO ${ }^{2}$, N.A. PASHCHIN ${ }^{1}$, O.L. MIKHODUJ ${ }^{1}$ and A.V. CHERKASHIN ${ }^{1}$ \\ ${ }^{1}$ E.O. Paton Electric Welding Institute, NASU \\ 11 Kazimir Malevich Str., 03680, Kiev, Ukraine. E-mail: office@paton.kiev.ua \\ ${ }^{2}$ Institute of Electrodynamics, NASU \\ 56 Pobedy Ave., 03680, Kiev, Ukraine
}

\begin{abstract}
The residual welding stresses negatively affect the fatigue limit of welded joint, being the main cause for brittle fracture of metal, i.e. corrosion cracking. Therefore, the development of effective methods for control of welding stresses, characterized by low energy consumption and relatively simple realization, is traditionally an urgent problem for modern production. At the present time the methods for reducing welding stresses became widespread, based on the influence of pulses of electric current and magnetic field. Moreover, each of the methods has its advantages and disadvantages, and evaluation of their efficiency in the control of residual welding stresses represents an urgent problem. In the work the comparative evaluation of efficiency of control of residual stresses of AMg6 alloy of welded plates was carried out at treatments by pulsed electromagnetic field (TPEMF) and pulsed current (EDT), applying planar inductors. Using the method of electron speckle interferometry it was revealed that TPEMF and EDT reduce the initial level of welding stresses in the zone of pulsed effects to $100 \% .16$ Ref., 1 Table, 4 Figures.
\end{abstract}

K e y w or d s : electrodynamic and magnetic pulse treatment, aluminium alloy, welded joint, electron speckle interferometry, efficiency of treatment, residual stresses, electroplastic effect, current density, planar inductor

The investigations of influence of residual welding stresses on strength of welded joints, especially at cyclic loading are traditionally relevant in engineering practice of service of metallic structures. It is connected with the fact that welding stresses negatively affect the fatigue limit of welded joint, increasing the rates of fatigue crack propagation $[1,2]$. In this case the tensile welding stresses at their interaction with corrosive-active environment are the main cause for brittle fracture of metal, i.e. corrosion cracking [3].

Traditionally, technological operations on reduction of welding stresses are sufficiently labor-intensive and are restricted by thermal or mechanical effect on the metal of welded joint. The development of efficient methods for control of welded stresses, characterized by low power consumption and relatively simple realization, is urgent for modern production.

In scientific and technical publications the results of investigations of influence of pulses of electric current (PEC) and magnetic field (PEMF) on relaxation of technological stresses [4-6], including residual welding stresses, are presented [7, 8]. Each of the effects mentioned above, has its advantages and disadvantages and the evaluation of efficiency of control of residual stresses is a relevant problem.

The aim of the present work was the comparative evaluation of parameters of treatment using pulsed electromagnetic field (TPEMF) and pulsed current (EDT) on reduction of residual stresses in welded joints of aluminium alloy.

Methods of investigations. To carry out investigations the specimens of welded joint and base metal of annealed aluminium alloy AMg6 were used. The mode of preliminary annealing of billets (heating to $320{ }^{\circ} \mathrm{C}$ during $1.5 \mathrm{~h}$ and furnace cooling ) guaranteed the absence of technological stresses in metal.

The specimens of welded joint with the weld of $250 \mathrm{~mm}$ length were produced of two sheet billets of $360 \times 250 \times 4 \mathrm{~mm}$ size in a single pass using automatic TIG welding (Ar) in the installation ASTV-2M. The welding mode at the arc voltage $U_{\mathrm{a}}=18 \mathrm{~V}$, current $I_{\mathrm{a}}=200 \mathrm{~A}$ and speed $v_{\mathrm{w}}=3.1 \mathrm{~mm} / \mathrm{s}$ provided the guaranteed penetration along the whole length of the joint. The schemes of performance of TPEMF and EDT of welded joint are presented in Figure 1.

TPEMF of weld was performed according to the scheme presented in Figure 1, $a$. The inductor $L$, designed as a single-turn plane circuit, was moved along the longitudinal axis of the weld at a pitch of $15 \mathrm{~mm}$ after each discharge cycle [8]. The outer diameter of the inductor $D_{\text {out }}=45 \mathrm{~mm}$, the inner $d_{\text {inn }}=15 \mathrm{~mm}$. The inductor was rigidly fixed on the surface of welded plate, which excluded its movement during the discharge cycle. The magnetic field of the inductor was 
excited by a current pulse generated during discharge of the capacitor on the electric circuit composed of the circuit inductivity and active resistance of conductors. The charge of the capacitor $\mathrm{C}$ with electric capacity of $600 \mu \mathrm{F}$ was carried out from the source of a constant voltage of $3 \mathrm{kV}$. The commutation of electric circuit was performed by the control key $K$. During passing of electric current through the planar inductor, the magnetic field was excited, which, interacting with electric conductive plate, excited eddy currents. The interaction of magnetic field and the eddy currents induced by it led to generation of electrodynamic force, which being applied to the surface, generated the socalled magnetic pressure. The maximum amplitude of discharge current $I_{\mathrm{d}}^{\mathrm{PEMF}}$ and the duration of its effect $t_{\mathrm{d}}^{\mathrm{PEMF}}$, recorded using the Rogowski coil [8], were, respectively, $35 \mathrm{kA}$ and $0.5 \mathrm{~ms}$. The scheme of TPEMF presented above provided the pulsed electromagnetic pressure $P^{\mathrm{PEMF}}$ to the local area of a weld at a simultaneous passing of electric current through that area [9].

The effect of $P^{\mathrm{PEMF}}$ initiated the localized fields of tensile deformations in the treated metal, the interaction of which with plastic welding compressive deformations facilitated the decrease in the level of residual stresses. The effect of electric current provided the increase in ductile properties of metal and the reduction of its resistance to deformation.

The EDT was performed during passing of pulsed current through the contact area of the copper electrode 2 , being a part of the electrode device, with the surface of welded joint 1 (Figure 1, b). The electrode device included a planar multi-turn inductor $L$ of diameter $D_{\mathrm{e}}=100 \mathrm{~mm}$, and the electrode 2 , rigidly connected to the disc 3 of a non-ferromagnetic material. The interaction of magnetic field of the inductor and the eddy currents induced by it in the disc 3 results in generation of electrodynamic force, which transfers pressure $P^{\mathrm{EDT}}$ through the electrode 2 to the contact area simultaneously with passing of pulsed current through it. The commutation of electric circuit consisting of capacity, inductance of the inductor and active resistance of the conductors, was realized by the control key $K$. The EDT was performed at the values of $U_{\text {ch }}=500 \mathrm{~V}$ and $C_{\text {ch }}=6600 \mu \mathrm{F}$ and $I_{\mathrm{d}}^{\text {PEMF }}$ and $t_{\mathrm{d}}^{\mathrm{PEMF}}$ were, respectively, $3.1 \mathrm{kA}$ and $1.0 \mathrm{~ms}$ [10]. The effect of EDT, as well as in the case of TPEMF, is determined by summing the two effects, the first of which is the pulsed pressure $P^{\mathrm{EDT}}$ preset by passing PEC through the inductor $L$, disc 3 and electrode 2, the value of which reaches $20 \mathrm{kN}$ at $U_{\text {ch }}=500 \mathrm{~V}$. The second is the electric current of a specified density which spreads from the contact area. The treatment of

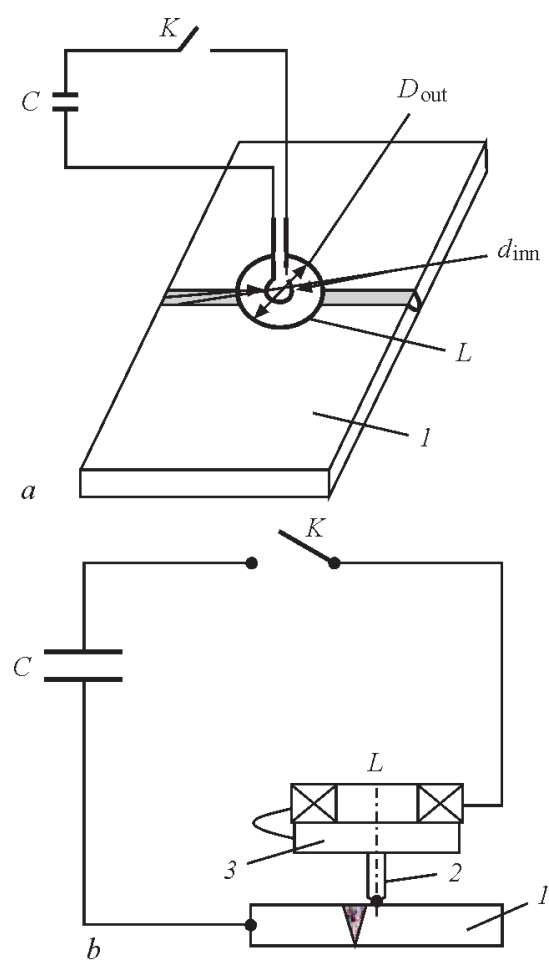

Figure 1. Scheme of discharge circuit: $a-$ TPEMF [8]; $b-$ EDT (see description in the text)

weld was performed according to the scheme, similar to that realized at TPEMF: the inductor was moved along the fusion line at the pitch of 5-7 mm after each PEC. In general, the mechanism of influence of $P^{\mathrm{EDT}}$ on welded joint is similar to that realized at TPEMF.

The difference of EDT from TPEMF is in the fact that in the first case to the treated metal a load is applied, concentrated in the zone of current-conducting end of the electrode 2 (Figure $1, b$ ), and in the second - the load is distributed over the surface of the inductor $L$ contacting with the treated metal (Figure $1, a$ ).

To evaluate the influence of TPEMF and EDT on the stressed state of AMg6 alloy without account for the welding stresses, the treatment of plates of the base metal of $360 \times 500 \times 4 \mathrm{~mm}$ sizes was performed. TPEMF and EDT were carried out in the center of the plates by single PEC at the modes applied for treatment of welded joints. In the process of treatment of specimens the evaluation of Joule heating [9], initiated by passing PEC and PEMF through the treated material, was made. In case of TPEMF, for evaluation of changes in temperature, temporary distribution of current density and stressed state of the plate without a weld the numerical modeling was applied using finite element method.

During EDT the change in the temperature of Joule heating in the zone of electrodynamic effects was registered using thermocouples [11].

For TPEMF and EDT of welded plates the specialized assembly devices were used providing position- 
ing of the inductor and a guaranteed contact of the electrode with the treated surface. The stressed state of welded plates was determined using the method of electron speckle interferometry based on the measurement of displacements, arising at the elastic unloading of metal volume in the investigated points on the surface of specimens caused by drilling blind holes. [12].

Results of experiments and their discussion. The analysis of results of evaluation of change in values of the temperature of surface of plates $T_{\text {surf }}$ under the inductors $L$ (Figure 1, $a$ ) at TPEMF, as well as in the zone of contact interaction of the electrode 2 (Figure $1, b$ ) in the EDT zone, showed influence of Joule heating on the stressed state of specimens at the methods of treatment described above is almost absent. Thus, the peak values of $T_{\text {surf }}$ at TPEMF did not exceed $25^{\circ} \mathrm{C}$ [8], while at EDT $-30^{\circ} \mathrm{C}$ [11], which has no significant influence on the stressed state of AMg6 alloy [10].

The evaluation of change in PEC density with time, i.e. $j$ in the welded plate over the period of its action $t$ at TPEMF and EDT, was carried out (Figure 2). The dependence $j=f(t)$ at TPEMF was determined by numerical method realized in the finite element formulation. The distribution of $j=f(t)$ at TPEMF, presented in curve 1 [8], has the form of attenuated sinusoid, which is characteristic for the discharge circuit with active resistance (the role of which is performed by welded specimen), which is composed of the capacitor $C$ and inductance $L$. The values of $j$ during the whole period of discharge of the capacitor are within the range of $1-4 \mathrm{kA} / \mathrm{mm}^{2}$. This indicates the fact that at TPEMF the reduction in resistance of material to deformation takes place as a result of electroplastic effect (EPE) [9]. The EPE is determined as a specific action of PEC at $j \geq 1 \mathrm{kA} / \mathrm{mm}^{2}$, initiating changes of plastic properties of the material due to interaction of conductance electrons with the defects of crystal lattice (dislocations), thus increasing their mobility [13]. This creates conditions for development of inelastic

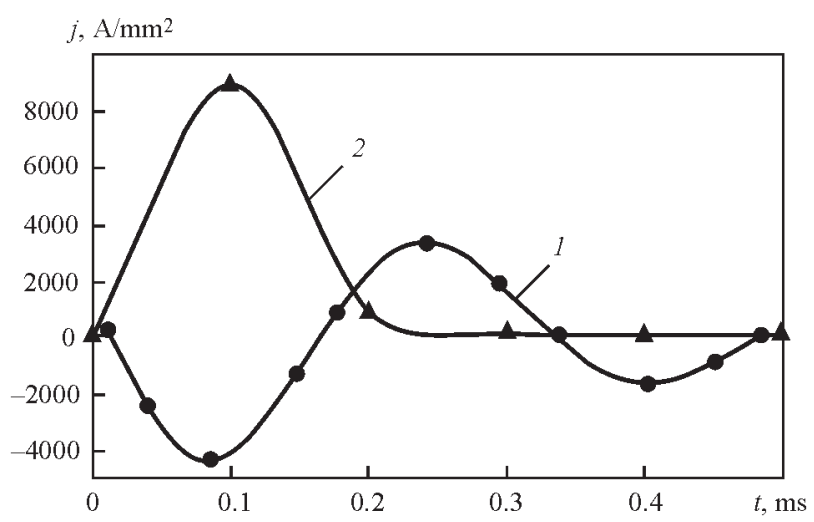

Figure 2. Distribution of current density in the annealed plate of AMg6 alloy $\delta=4 \mathrm{~mm}$ after TPEMF [8] (curve 1) and EDT (2) deformations (microshears) in the area of defects of crystalline structure, leading to relaxation of residual stresses of the first type at the macrolevel.

The distribution of $j$ at EDT was registered in the phase of increment of electrode effect on the treated surface of the plate. The unipolar character of the dependence $j=f(t)$ at EDT (curve 2), calculated according to the methods, shown in the [11], is preset by configuration of discharge circuit and is determined by joint effect of dynamic load at indentation of electrode into the treated material, as well as by direct passing of PEC through it in the period of discharge cycle. Moreover, if at contact-free TPEMF, where the pressure of $P^{\mathrm{TPEMF}}$ is realized only by electrodynamic forces and PEC passes through the constant cross section of the plate, then at EDT the change of current in the area of contact interaction with the treated surface of electrode occurs, directly depending on the change of $P^{\mathrm{EDT}}$ in time. The change in the area of electrical contact of electrode with the plate is determined by the laws of elastic-plastic contact of interaction of the system «sphere-plane» at a zero initial gap [14]. The temporary ratios of values of pulsed current and contact area of electrode, determining the change of $j$ at EDT, are presented in the work [11]. At the initial stage of increment of pulsed current, corresponding to the period of time $t=0-0.1 \mathrm{~ms}$ (curve 2), the area of electrical contact of the pair «electrode-metal» is minimal, which causes an increment of values of $j$ up to $9.0 \mathrm{kA} / \mathrm{mm}^{2}$. With increase in contact area to the maximum value at the time $t=0.1-0.6 \mathrm{~ms}$, the value $j$ monotonously decreases to $0.15 \mathrm{kA} / \mathrm{mm}^{2}$.

Analyzing the distribution $j=f(t)$ at EDT in curve 2 , it can be concluded that at the initial phase of indentation of electrode at $t=0-0.2 \mathrm{~ms}$ the EPE also takes place, the influence of which is minimal in the period of $t=0.2-0.5 \mathrm{~ms}$. The efficiency of EDT, as is mentioned above, is determined by the combined effect of current and dynamic components of the process. Thus, the dynamic load creates conditions for breakthrough of barriers by dislocation factions, and a direct passing of PEC of high density provides propagation of dislocations in a directed flow of conduction electrons, which corresponds to the concept of electron-dislocation interaction [9]. In detail the mechanism of effect on the conductive materials at EDT is described in the work [15].

At the comparison of curves 1 and 2 in Figure 2 it can be seen that considering the fact that the influence of EPE on the structure and ductility of the material directly depends on the value $j$ [9], the contribution of EPE to relaxation of stresses at EDT is more expressed, than at TPEMF. This is connected with peculiarities of passing PEC in the discharge circuits used 
at both types of treatment. Thus, the absolute value of current density at TPEMF is not more than $4 \mathrm{kA} /$ $\mathrm{mm}^{2}$, whereas at EDT it reaches $9 \mathrm{kA} / \mathrm{mm}^{2}$. Moreover, for TPEMF the bipolar PEC and for the EDT the unipolar one are characteristic, which affects the efficiency of electric pulsed effects. Thus, in the work [16] it is shown that at the same amount of electricity and amplitude of PEC, passed through the loaded specimen, the bipolar pulses cause a lower relaxation (jump) of stresses, than unipolar ones. This, according to the authors' opinion, is caused by the fact that the successive PEC of different polarity counteract each other initiating the movement of dislocations in the opposite directions due to which the resultant of the Burgers vector is lower than that at the unipolar PEC.

The comparative evaluation of distributions of tangential stresses $\sigma_{\theta}$ after TPEMF and EDT was carried out on the surface of the annealed plates of AMg6 alloy (Figure 3). The scheme of applying the effect of TPEMF and EDT to the plate as well as location on the specimen of cross-section, where $\sigma_{\theta}$ was determined, is shown in Figure 3, $a$. The diagram of $\sigma_{\theta}$ after TPEMF [8] (Figure 3, b, curve 1) has a form of a sinusoid with two zones of tension balanced by the compression zone located between them. The first zone of tension with a maximum value of $\sigma_{\theta}=$ $=7 \mathrm{MPa}$ was located at the area $l=0-8 \mathrm{~mm}$ of the plate cross-section, located under the center of the inner hole of the inductor. The second zone of tensile stresses with the maximum value $\sigma_{\theta}=18 \mathrm{MPa}$, was located in the area of the plate $l=24-45 \mathrm{~mm}$ from the center of the inductor. The zone of compressive stresses with the maximum value $\sigma_{\theta}=-35 \mathrm{MPa}$, was located in the area $l=8-24 \mathrm{~mm}$ from the center of the hole. The maximum effects fell on the area of section of the plate surface located below the generatrix of the inner cylindrical surface of the inductor $L$ of $d_{\text {inn }}$ diameter. Analyzing the distribution of $\sigma_{\theta}$ in curve 1 , it can be concluded that TPEMF (at the preset process parameters) facilitates compressive stresses, reaching not more than $0.25-0.3 \sigma_{0.2}$ in AMg6 alloy.

The distribution of stresses after EDT [11] (Figure $3, b$, curve 2 ), is characterized by compression area with the maximum value to $\sigma_{\theta}=-160 \mathrm{MPa}$, localized in the zone of contact interaction of electrode 2 (Figure $1, b)$ with the treated surface. The compression zone is balanced by a monotonically decreasing field of tensile stresses with the peak value $\sigma_{\theta}=60 \mathrm{MPa}$, located at the $15 \mathrm{~mm}$ distance from the longitudinal axis of the electrode. Analyzing the distribution of $\sigma_{\theta}$ shown in curve 2, it can be concluded that EDT stimulates compressive stresses in the $\mathrm{AMg} 6$ alloy, close to the value of $\sigma_{0.2}$ for AMg6 alloy. The distribution of longitudinal (relatively to the weld axis) $\sigma_{x}$ compo-
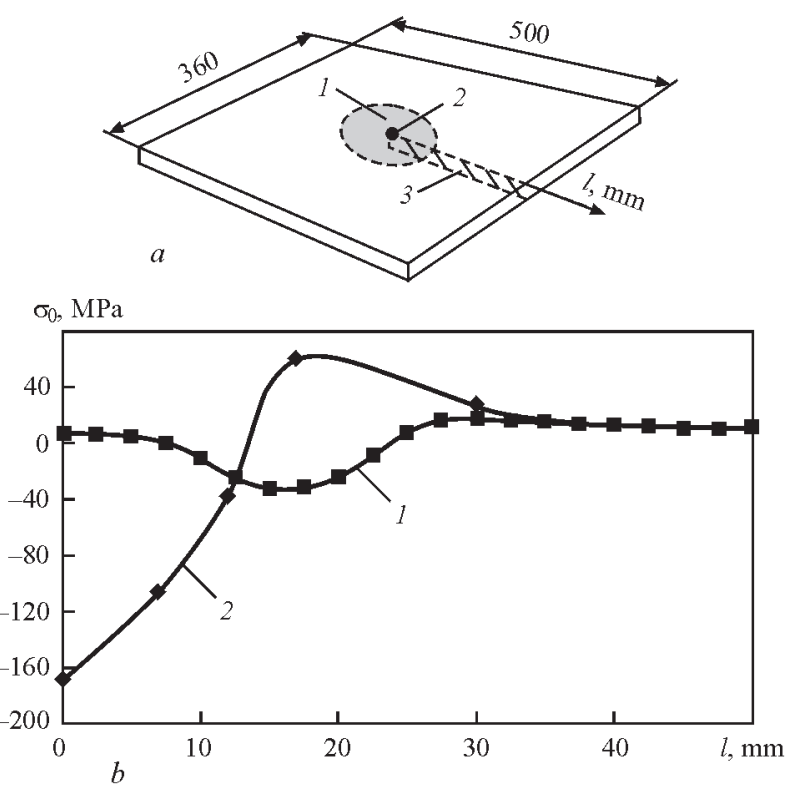

Figure 3. Tangential stresses $\sigma_{\theta}$ in the annealed plate of AMg6 alloy $\delta=4 \mathrm{~mm}$ after TPEMF [8] and EDT [11]: $a$ - investigated plate $(1-$ zone of TPEMF effect; 2 - EDT; 3 - section in which $\sigma_{\theta}$ was determined); $b$ - distribution of $\sigma_{\theta}$ after TPEMF (curve 1), after EDT (2)

nent of residual welding stresses in the central cross section of plates before and after TPEMF and EDT, is shown in Figure 4. It is seen from Figure that before treatment the maximum values $\sigma_{x}$ are close to the conditional yield strength $\sigma_{0.2}$ of AMg6 alloy. Comparing the appearance of diagrams $\sigma_{x}$ before (curve 1) $[7,8]$, as well as after TPEMF (curve 2) [8] and EDT (curve 3) [7], it can be seen that the pulsed effects influence the distribution of stresses in the treated section.

Analyzing the distribution of $\sigma_{x}$ presented in curve 2 , it can be seen that the area of effective influence at TPEMF is comparable with the inner diameter of planar inductor, the value of which is $15 \mathrm{~mm}$. The arrangement of inductor was preset in such a way that the highest density of power lines of TPEMF fell on

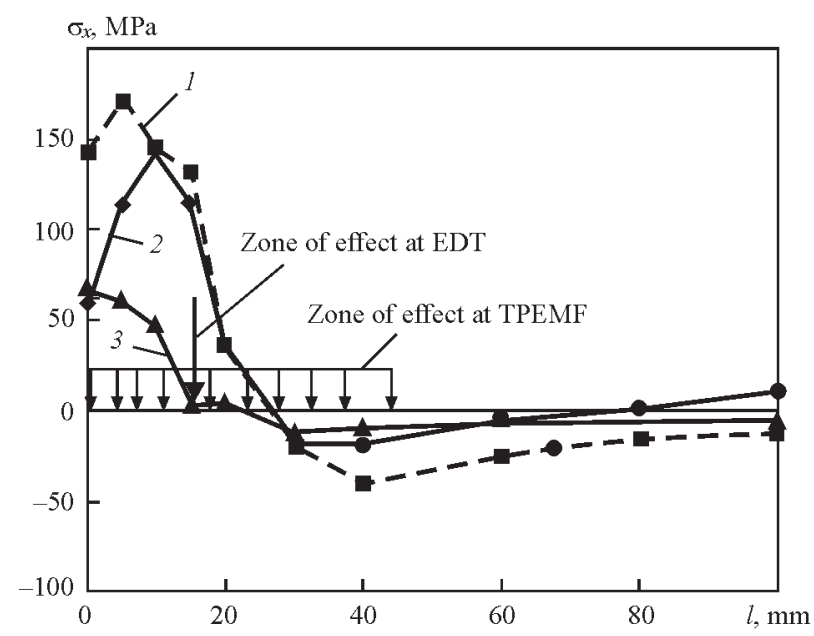

Figure 4. Distribution of welding residual stresses $\sigma_{x}$ in the plate of AMg6 alloy $\delta=4 \mathrm{~mm}$ without treatment (curve 1), after TPEMF [8] (2) and EDT (3) 
Values of electric and mechanical parameters of TPEMF and EDT

\begin{tabular}{|c|c|c|c|c|c|c|c|c|}
\hline $\begin{array}{c}\text { Type of } \\
\text { treatment }\end{array}$ & $\begin{array}{c}\text { Charge } \\
\text { capacity } C_{\mathrm{ch}}, \\
\mu \mathrm{F}\end{array}$ & $\begin{array}{c}\text { Charge voltage } \\
U_{\mathrm{ch}}, \mathrm{V}\end{array}$ & $\begin{array}{c}\text { Discharge } \\
\text { current } \\
I_{\mathrm{d}}, \mathrm{kA}\end{array}$ & $\begin{array}{c}\text { Charge power } \\
E_{\mathrm{ch}}, \mathrm{J}\end{array}$ & $\begin{array}{c}\text { Stress before } \\
\text { treatment } \sigma_{0}, \\
\mathrm{MPa}\end{array}$ & $\begin{array}{c}\text { Stress after } \\
\text { treatment } \sigma_{\mathrm{tr}} \text { r } \\
\mathrm{MPa}\end{array}$ & $\begin{array}{c}\text { Decrease } \\
\text { in stress } \\
\Delta \sigma, \mathrm{MPa}\end{array}$ & $\begin{array}{c}\text { Specific } \\
\text { power } \\
\text { of treatment } \\
E_{\mathrm{s}} / \Delta \sigma, \mathrm{J} / \mathrm{MPa}\end{array}$ \\
\hline TPEMF & 600 & 3000 & 35.0 & 2700 & 148 & 52 & 96 & 28.1 \\
\hline EDT & 6600 & 500 & 3.0 & 825 & 130 & 5 & 125 & 6.6 \\
\hline
\end{tabular}

the weld metal, which determined the maximum efficiency of treatment of the mentioned area. So, the value $\sigma_{x}$ in the weld zone reduced to $50 \mathrm{MPa}$, which makes $35 \%$ of values of stresses before TPEMF. At the distance from the center of the weld for $5 \mathrm{~mm}$ the values $\sigma_{x}$ make $65 \%$ of initial ones, and at the distance of $15 \mathrm{~mm}$ the TPEMF almost does not influence the distribution of $\sigma_{x}$. From the comparison of curves 1 and 2 in Figure 4 it follows that the effectiveness of TPEMF on welded joint is monotonously decreased towards edges of the inner diameter of the inductor. Thus, if is accepted the area of tension diagram $\mathrm{S}_{\sigma+}$ on the curve 1 (Figure 4 ) as over $100 \%$, than as the result of TPEMF (curve 2) the value $\mathrm{S}_{\sigma+}$ is reduced by $23 \%$.

Analyzing the distribution of $\sigma_{x}$ after EDT (curve 3) it can be seen that the influence of the latter on decrease in stresses is more expressed as compared to the effect of TPEMF. The efficiency of effect at EDT is obviously determined by the character of concentrated energy input into the treated metal (unlike the distributed effect at TPEMF) and the ratio of value $P^{\mathrm{EDT}}$ and amplitude of pulsed current. Thus, after EDT the reduction of tensile $\sigma_{x}$ occurs in the area of effect (arrow in Figure 4) from 120 to $5 \mathrm{MPa}$. The character of distribution of $\sigma_{x}$ after EDT is connected with the fact that in the discharge cycle the electrodynamic effect initiates the wave of tensile deformation in the near-weld zone [15], the interaction of which with residual stresses of weld causes a localized plastic deformation, which determines the character of $\sigma_{x}$ distribution after treatment of the plate. The EDT of butt welded joint of AMg6 alloy causes a decrease in residual welding stresses in the treatment zone to the values close to zero. Therefore, the value of $\mathrm{S}_{\sigma^{+}}$as a result of EDT (curve 3) is reduced by $76 \%$.

The comparative evaluation of power consumption, required for reduction of stresses as a result of a single pulsed effect, realized at the two described types of treatment, was carried out. As the evaluation characteristic, the specific stored energy $E_{\mathrm{s}}$ of the capacitor was used, consumed for reducing the level of stressed state $\Delta_{\sigma}$ per one $\mathrm{MPa}-E_{\mathrm{s}} / \Delta_{\sigma}$. The values of $\Delta_{\sigma}$ for TPEMF and EDT were preset on the basis of maximum of values $\sigma_{x}$, registered before treatment $\sigma_{0}$ and after $\sigma_{\text {tr }}$ in the area of pulsed effect (Figure 4):

$$
\Delta \sigma=\sigma_{0}-\sigma_{\mathrm{tr}}, \mathrm{MPa}
$$

The calculation of values $E_{\mathrm{s}}$ was performed using the expression for the stored energy of the capacitor [4]. The values of electrical and mechanical parameters for the described effects, used for evaluation of $E_{\mathrm{s}} / \Delta_{\sigma}$ are presented in the Table.

Analyzing the data of the table, it can be seen that the value of the stored energy of EDT, consumed for reduction of residual welding stresses in the AMg6 alloy per one $\mathrm{MPa}$, is four times lower than the similar value at TPEMF. This is an essential factor in selecting the type of treatment of long welded joints, where the number of effects can be hundreds and thousands.

It is necessary to mention the technological features of TPEMF application, that can be seen when comparing the values of $U_{\text {ch }}$ for two types of treatment. This is connected, first of all, with the use of high voltage (over $1000 \mathrm{~V}$ ) at TPEMF for inductors power supply, which results in increasing cost of electrotechnical equipment, possible undesirable electrophysical phenomena (breakdown of electrical insulation, spark processes and etc.). In the use of TPEMF it is assumed that the inductor is a consumable element of the equipment complex. Taking into account the most of positive results on redistribution of welding stresses after TPEMF, presented in Figure 4, it would be appropriate to carry out investigations on optimization of the design of inductor and treatment modes, aimed at intensification of TPEMF effect on welded joints of structural materials.

Among the disadvantages of EDT a high degree of localization of pulsed current effect should be mentioned, which requires a great number of electrode movements along the weld line as compared to TPEMF. The further investigations on improving the efficiency of EDT should be directed both to expanding the zone of influence of effect of discharge current, as well as to the development of technological measures for improving the contribution of EPE to the pulsed effect, aimed at regulating the stressed state of welded joints. Moreover, for two types of treatment it is relevant to increase their power characteristics, aimed at transformation of tensile stresses into compressive ones.

Based on the carried out work it can be concluded that the two considered methods are characterized by a significant potential for the control of residual 
stress-strain state of welded joints, which implies carrying out further investigations on their improvement.

\section{Conclusions}

1. The comparative evaluation of efficiency of control of residual stresses of welded plates of AMg6 alloy was carried out at treatments using pulsed electromagnetic field (TPEMF) and pulsed current (EDT), performed with planar inductors.

2. It was established that TPEMF and EDT allow reducing the initial level of welding stresses in the area of pulsed effects, respectively, by 65 and $100 \%$.

3. It was established that the value of the stored energy of EDT, consumed for reduction of welding residual stresses in AMg6 alloy per one $\mathrm{MPa}$, is four times reduced than the similar value at TPEMF.

4. It was shown that unlike EDT, the use of TPEMF, is connected with the use of high voltages (over 1000 $\mathrm{V})$ for the power supply of inductors, which results in increase in the cost of electrical equipment, possible undesirable electrophysical phenomena (breakdown of electrical insulation, spark processes, etc.).

5. It was shown that TPEMF and EDT are characterized by a significant potential for the control of residual stress-strain state of welded joints, which involves carrying out further investigations for their improvement.

1. Trufyakov, V.I. (1973) Fatigue of welded joints. Kiev: Naukova Dumka.

2. Trufyakov, V.I., Mikheev, P.P., Kuzmenko, A.Z. (1980) Influence of scale factors and residual welding stresses on rate of fatigue crack propagation. Problemy Prochnosti, 6, 20-22, 30.

3. Petuchkov, V.G., Kudinov, V.M., Fadeenko, Yu.I. (1993) Explosion treatment of welded joints of metal structures. Moscow: Metallurgiya.
4. Antonov, Yu.A., Ragozin, Yu.I. (2001) Pulse method of residual stress relieving. Fizika i Khimiya Obrab. Materialov, 3, 91-95.

5. Tang, F., Lu, A.L., Mei, J.F. et al. (1998) Research on residual stress reduction by a low frequency alternating magnetic field. J. of Materials Processing Technology, 74, 255-258.

6. Stepanov, G.V., Babutsky, A.I. (2007) Modeling of stress relaxation under action of high density pulse current. Problemy Prochnosti, 2, 113-120.

7. Lobanov, L., Pashchin, N., Pivtorak, V. et al. (2014) Application of local current pulses for determination and control of residual stresses. Advanced Materials Research, 996, 386-391.

8. Stepanov, G.V., Babutsky, A.I., Mameev, I.A. et al. (2011) Redistribution of residual welding stresses due to treatment by pulse electromagnetic field. Problemy Prochnosti, 3, 121-131.

9. Baranov, Yu.V., Troitsky, O.A., Avramov, Yu.S. (2001) Physical principles of electroplastic treatment and new materials. Moscow: MGIU.

10. Lobanov, L.M., Pashchin, N.A., Cherkashin, A.V. et al. (2012) Efficiency of electrodynamic treatment of aluminium alloy AMg6 and its welded joints. The Paton Welding J., 1, 2-6.

11. UDK 658.562: Report (final) of research activity on project $\mathrm{R}$ 7.3.1: To develop the technology and equipment for prompt non-destructive determination of residual stresses in welded structures based on application of local current pulse and electron speckle interferometry. Nat. Registr. 011U003481. Kiev: PWI.

12. Lobanov, L.M., Pivtorak, V.A., Savitsky, V.V. et al. (2006) Procedure for determination of residual stresses in welded joints and structural elements using electron speckle interferometry. The Paton Welding J., 1, 24-29.

13. Kravchenko, V.Ya. (1966) Effect of directed electron flow on moving dislocations. Zh. Experimentalnoj i Teoreticheskoj Fiziki, 51, Issue 6(12), 1677-1688.

14. Johnson, K. (1989) Mechanics of contact interaction. Moscow: Mir.

15. Lobanov, L.M., Pashchin, N.A., Mikhoduj, O.L. et al. (2012) Effectiveness of various variants of electrodynamic treatment of AMg6 alloy and its welded joints. The Paton Welding J., 12, 26-31.

16. Troitsky, O.A., Kalymbetov, P.U. (1981) Dependence of electroplastic effect in zinc on isolated pulse duration. Fizika Metallov i Metallovedenie, 51(Issue 5), 1056-1059.

Received 30.06.2016 